\title{
RESEARCH OF THE MODES OF FULL COMPENSATION OF REACTIVE POWER IN A THREE-PHASE POWER SUPPLY SYSTEM
}

Introduction The article is devoted to the issues of current balancing and reactive power compensation in a three-phase power supply system. Optimal in all these respects is the mode of full compensation of reactive power, by which we mean such a symmetrical mode, in which only active power is consumed from the source. The task of calculating the mode of full reactive power compensation is non-linear and can be solved using non-linear optimization methods based on the adopted parameters and optimization criteria. The objective of the article is to develop a visual model of the power supply system with an unbalanced load, in which current balancing and reactive power compensation is performed using a symmetrical-compensating device, which parameters are determined using search non-linear optimization tools and modern computer mathematics software packages. The purpose of the article is to research the modes of full compensation of reactive power in a three-phase power supply system with a linear asymmetric load in order to identify the ambiguity of solving the problem of synthesizing parameters of a reactive power compensator. Methodology of research consists in the development of a visual model of a power supply system that feeds unbalanced load. As a symmetrical compensating device, capacitors connected between the phases of the transmission line are used. The model is controlled by a program that launches the model and performs optimization and selection of optimization variable values. The optimization values are the capacitors of the symmetry-compensating device. The optimization criterion is a spherical metric consisting of the reactive powers of each source of electricity. Results lead depending on the choice of the initial values of the optimization variables, the optimization process enters two modes of full compensation of reactive power-main and additional. The main mode is characterized by small values of capacitors and small values of currents, and in the additional mode, these values of the system and operational parameters reach extremely large values that are unacceptable for practical use. Originality lies in the fact that in terms of optimization theory this means that there is no global optimum in the solution of the problem of full compensation, however, there are two local optimums. Both modes are stable, as evidenced by modeling on the SPS-model of the system in the time domain in the space of state variables. Practical significance of the work lies in the fact that when designing a microprocessor system that optimizes the operating mode of the power supply system, it is necessary to envisage the situation of additional mode. References 10, tables 1, figures 6.

Key words: reactive power, reactive power compensator, search optimization, visual model, three-phase power supply system.

Розглядається рімення задачі визначення параметрів режсмів повної компенсації реактивної потужності для трифазної системи 3 лінійним несиметричним навантаженням. Дослідження, проведені за допомогою SimPowerSystems-моделі і методу деформованого багатогранника, показали, що в залежсності від початкових умов для змінних оптимізації, процес оптимізації може призводити до двох різних рішень. Основний режим повної компенсації характеризується істотним зменшенням втрат в системі. Другий же, додатковий режим повної компенсації може характеризуватися неприйнятними на практиці зростанням струмів і напруг в системі електропостачання. Бібл. 10 , табл. 1 , рис. 6.

Ключові слова: реактивна потужність, компенсатор реактивної потужності, пошукова оптимізація, візуальна модель, трифазна система електропостачання.

Рассматривается решение задачи определения параметров режимов полной компенсации реактивной мощности для трехфазной системы с линейной несимметричной нагрузкой. Исследования, проведенные с помощью SimPowerSystems-модели и метода деформируемого многогранника, показали, что в зависимости от начальных условий для переменных оптимизации, процесс оптимизации может приводить к двум различным решениям. Основной режим полной компенсации характеризуется существенным уменьщением потерь в системе. Второй же, дополнительный режим полной компенсации может характеризоваться неприемлемыми на практике возрастаниями токов и напряжений в системе электроснабжения. Библ. 10, табл. 1, рис. 6.

Ключевые слова: реактивная мощность, компенсатор реактивной мощности, поисковая оптимизация, визуальная модель, трехфазная система электроснабжения.

Introduction. Problem definition and justification of its relevance. Balancing currents and voltages in threephase systems is one of the most important means of improving the quality of power supply and is an urgent task at the present stage $[1,2]$. Due to balancing, the amplitudes of the currents in the feeders of the power supply system are equalized, which contributes to a uniform loading of the sources of electrical power. In addition, the amplitudes of the currents in power transmission lines are reduced, which in turn means a decrease in power transmission losses, and, consequently, an increase in efficiency is ensured [3]. Optimal in all these respects is the mode of full compensation of reactive power, by which we mean such a symmetrical mode, in which only active power is consumed from the source. In this case, the reactive component of the power consumed from the source becomes zero, which is possible when a sinusoidal current is taken from the source that coincides in phase with the sinusoidal wave generated by the sinusoidal voltage source. Thus, in the mode of full compensation of reactive power, the power factor reaches the maximum unit value [6]. For a threephase power supply system, the full reactive power compensation mode should be extended to all three sources of electrical energy simultaneously.

Overview of recent publications on the topic. The results of solving the problem of balancing do not lead to the optimal mode, and it can be solved in the space of linear operators $[1,2]$. When solving the problem of full 
compensation of reactive power, the conditions of full compensation of reactive power in sources are added to the system of linear equations, and these conditions are non-linear. Therefore, in [1, 2], as well as in other sources [3-5], this problem did not find a complete solution. In the general case, the solution of the problem of full compensation of reactive power under the specified conditions is possible only with the help of optimization methods, as shown in [6]. The method of search optimization used in [6] allows to find mode parameters for the case of full compensation of reactive power using the visual model and the method of a deformable polyhedron [7]. Such a general approach opens up the possibility of studying reactive power compensation modes for power supply systems of any configuration and variations in network and load parameters.

The goal of the paper is study of modes in a threephase power supply system with a linear asymmetric load to identify the ambiguity of solution of the problem of synthesizing parameters of the compensator in the modes of full compensation of reactive power.

Presentation of the original material of the paper. A generalized three-phase power supply system, shown in Fig. 1 is considered.

The network of infinite power (NIP) is represented by the sources of sinusoidal voltage $e_{a}, e_{b}$ and $e_{c}$. Power transmission lines (PTL) in the form of complex resistances $z_{a}, z_{b}$ and $z_{c}$ bring energy to an asymmetrical load (AL) in the form of a star of complex resistances of an inductive nature $z_{n a}, z_{n b}$ and $z_{n c}$. The reactive power compensator (RPC) is represented by capacitors $C_{a b}, C_{b c}$, $C_{c a}$, connected in parallel with the load.

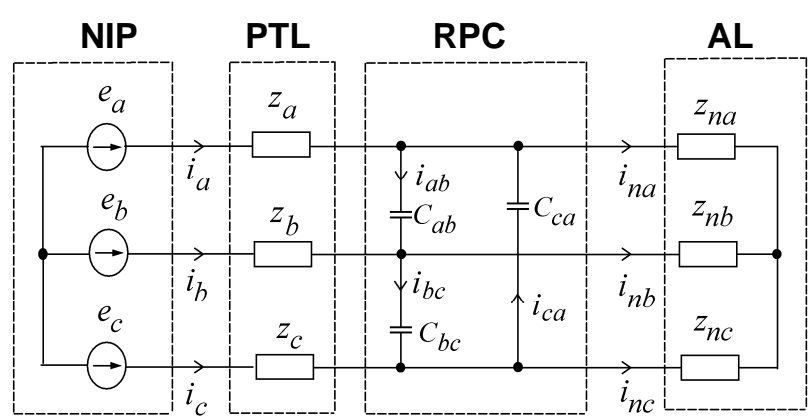

Fig. 1. Schematic circuit of a generalized three-phase power supply system

Determination of the capacitances of these capacitors is the task of synthesizing the parameters of the compensator, provided that the reactive power is fully compensated.

Main research material. The solution of the defined problem is feasible with the use of a visual model and search optimization in the SimPowerSystem (SPS) extension of the computer mathematics system MATLAB. Figure 2 shows a visual model of the power supply system.

Its appearance when using elements of the library of SimPowerSystem components practically coincides with the concept of the schematic circuit (Fig. 1).

Virtual current meters $i_{a}, i_{b}$ and $i_{c}$ are additionally introduced in PTL. The amplitudes of the voltage sources are assumed to be $100 \mathrm{~V}$, the frequency of voltages is $50 \mathrm{~Hz}$, $\omega=\omega=100 \pi$.

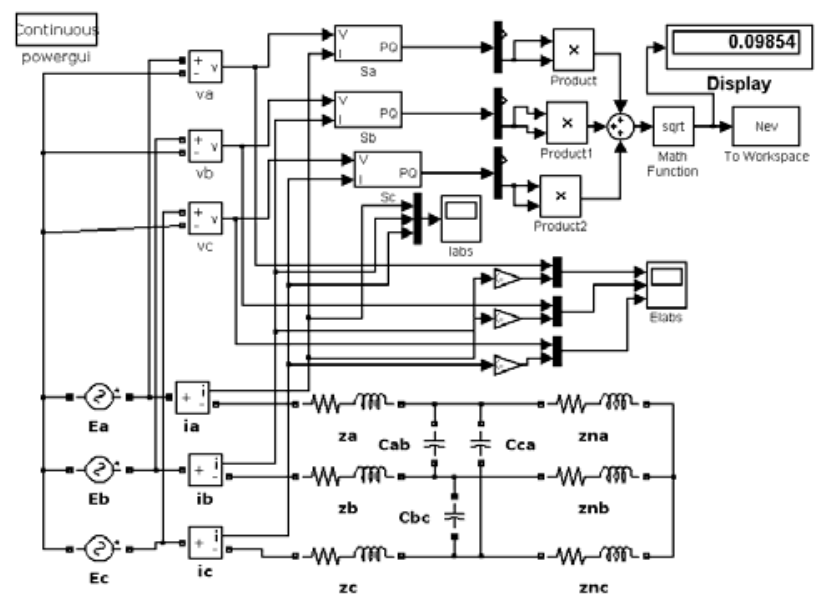

Fig. 2. Visual model of a three-phase power supply system

The complex resistances of all PTLs are assumed to be $z_{a}=z_{b}=z_{c}=0.1+j \omega 0.001 \Omega$. Complex load resistances: $z_{n a}=(0.7+j \omega 0.005) \Omega ; z_{n b}=(1+j \omega 0.01) \Omega$; $z_{n c}=(2+j \omega 0.04) \Omega$. With the specified parameters, the power supply mode of asymmetric load is characterized by asymmetric currents flowing in PTL:

$$
\begin{aligned}
& i_{a}=19.156-j 24.99=31.494 e^{j\left(-52.536^{\circ}\right)} A ; \\
& i_{b}=-25.84+j 17.11=30.995 e^{j\left(146.495^{\circ}\right)} A ; \\
& i_{c}=6.69+j 7.89=10.342 e^{j\left(49.705^{\circ}\right)} A .
\end{aligned}
$$

Virtual meters of active and reactive power, measuring the mode of the sources, give the following indicators for the total power given by the sources:

$$
\begin{aligned}
& S_{a}=(957.82+j 1249.88) V A ; \\
& S_{b}=(-94.75+j 1546.84) V A ; \\
& S_{c}=(174.35+j 486.81) V A .
\end{aligned}
$$

These indicators determine the following values of power factors for each of the sources of electricity:

$\cos \varphi_{a}=0.608 ; \quad \cos \varphi_{b}=-0.061 ; \quad \cos \varphi_{c}=0.337$.

The task mode for the first mode of full compensation of reactive power is carried out using a visual model, which is complemented by computational elements to determine the value of the objective function. The choice of the objective function itself is dictated by the formulation of the problem of complete compensation of reactive power for each of the sources of electricity.

The expression for the objective function is a spherical metric [8] composed of the reactive powers of each source of electricity:

$$
N=\sqrt{Q_{a}^{2}+Q_{b}^{2}+Q_{c}^{2}}
$$

This value is calculated in the model itself (Fig. 2), where only reactive powers are taken from the virtual $P Q$ meters, which are then squared, summed, and the square root is extracted from the sum, as shown on the model.

The resulting value of the objective function is transferred to the MATLAB system workspace using the To WorkSpace virtual block, from where it becomes available for program modules.

The first program module (Fig. 3,a) is the main program. The optimization variables are $C_{a b}, C_{b c}, C_{c a}$, 
representing the values of the capacitances of the compensator. These variables are declared global variables in the main program. Next the call of the built-in function of unconditional nonlinear optimization fminsearch() according to the deformable polyhedron method [8] comes. As the actual parameters, it is enough to specify two parameters: the name of the file function that provides the calculation of the value of the objective function, and the array of initial values of the optimization variables.

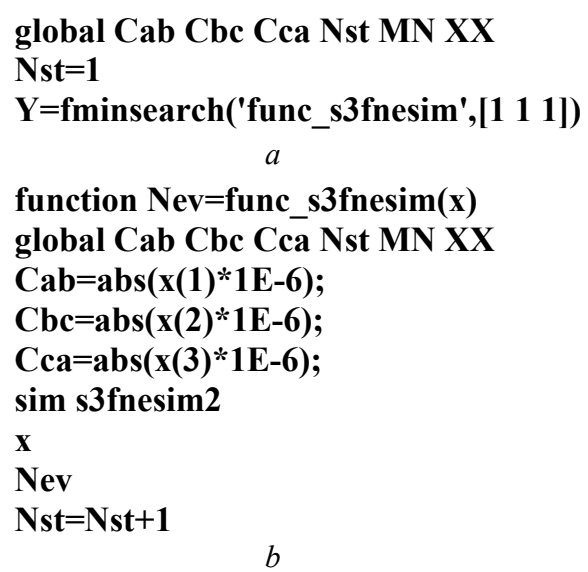

Fig. 3. Program codes:

$a$ - of the main program; $b$ - of file functions

The text of the second program module is shown in Fig. 3,b. The first line repeats the declaration of global variables. Next the operators are placed expressing the actual values of the capacitances of the compensator through the elements of the array of optimization variables. It is advisable to use the scale factor that converts the values of $x$ optimization variables, expressed in microfarads, to the values of capacitances $C_{a b}, C_{b c}, C_{c a}$, expressed in farads. This ensures that it is possible to avoid optimization on a set of optimization variables whose values approach zero.

After scaling, the sim operator follows, calling the visual model of the power supply system with a compensator to be executed. For the linear system under consideration, it is enough to run the model for only one period of the supply voltage, since for linear SPS-models, the default is a preliminary calculation of the steady state. During the SPS-model run, the value of the objective function is found during the period, which is then used by the optimization program itself.

The selection of the initial values of the optimization variables influences the progress of the optimization process. In the first variant, the vector $\boldsymbol{x}=[1,1,1]$ was adopted as the initial values of the variables of the optimization of the vector of initial values, that is, the capacitances of the capacitors were taken at the beginning of optimization $C_{a b}=C_{b c}=C_{c a}=1 \mu \mathrm{F}$.

Such a choice is explained by the desire to start optimization from the depicting point of the trajectory of the optimization process, separated from the initial asymmetrical mode at an insignificant distance. Indeed, the connection of such small capacitances does not have a significant impact on the original mode, and thus ensures a smooth transition from the initial mode to the optimization process. In this case, the optimization process ended after 268 runs of the SPS-model and led the solution to the following capacitor values of the compensator capacitances:

$$
C_{a b}=562.2 \mu \mathrm{F} ; C_{b c}=182.3 \mu \mathrm{F} ; C_{c a}=34.4 \mu \mathrm{F} \text {. }
$$

The amplitudes of the currents in PTLs with this became equal:

$$
I_{a m}=I_{b m}=I_{c m}=7.754 \mathrm{~A} .
$$

Thus, the mode of full compensation of reactive power allowed to reduce active losses in phases A, B, C, respectively, by $16.5,2.16$ and 21.78 times in comparison with the asymmetric mode.

The progress of the optimization process when the first mode is found clearly reflects the dependence of the value $N$ of the objective function on the sequence number $k$ of the SPS-model call per run (Fig. 4). Here you can clearly see the intervals of the graph, which are characterized by minor changes in the objective function, namely:

a) interval $k=0 \ldots 40$

b) interval $k=60 \ldots 180$;

c) interval $k=230 \ldots 268$.

Obviously, the first interval $k=0 \ldots 40$ is due to the increase in the values of the capacitances of the compensator from insignificant unit initial values to values at which they begin to significantly affect the reduction of reactive power in the power supply system.

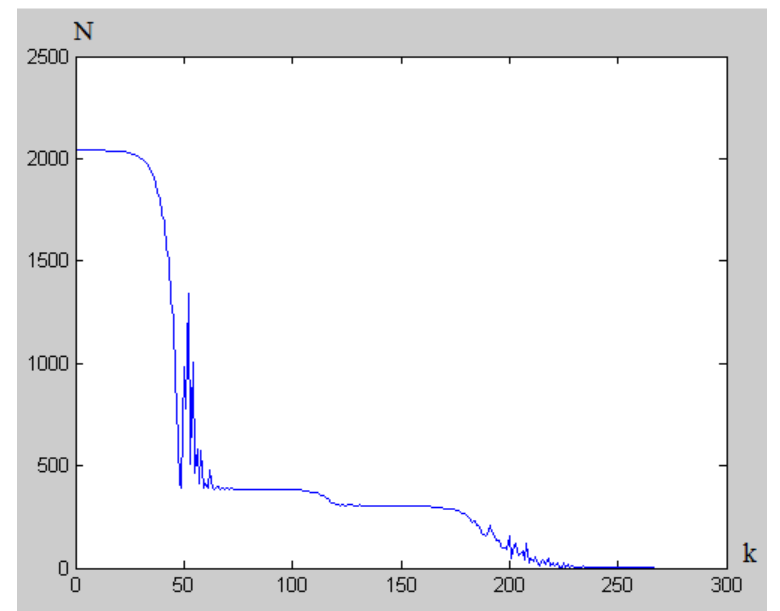

Fig. 4. Dependence of the objective function $N$ on the number of optimization step $k$ when finding the main mode of full compensation

The second interval is likely due to the peculiarities of the multidimensional surface, which reflects the behavior of the objective function on the set of values of the optimization variables. This interval takes about 120 calls to the SPS-model. The third interval for $k=230 \ldots$ 268 is due to bringing the already small value of the objective function to a value that satisfies the conditions of a given accuracy of reaching the solution. It can be changed by the option of running the fminsearch() optimization program itself. The analysis of the peculiarities of the considered optimization process led to the search for other initial values of the optimization variables that would shorten the solution time, providing a more favorable trajectory of the decision representation point. 
The solution of the problem for the second mode of full compensation of reactive power is carried out with the setting of significant initial values of the optimization variables. At the same time, the possibility of an accelerated arrival to the optimal solution from the practically short-circuit mode of the system with a reactive power compensator was expected.

For this purpose, the vector $\boldsymbol{x}=[4000,4000,4000]$ was selected as the initial one, which corresponds to the capacitance values $C_{a b}=C_{b c}=C_{c a}=4000 \mu \mathrm{F}$.

The corresponding plot of the value $N$ of the objective function versus the sequence number $k$ of the call to the SPS-model is shown in Fig. 5.

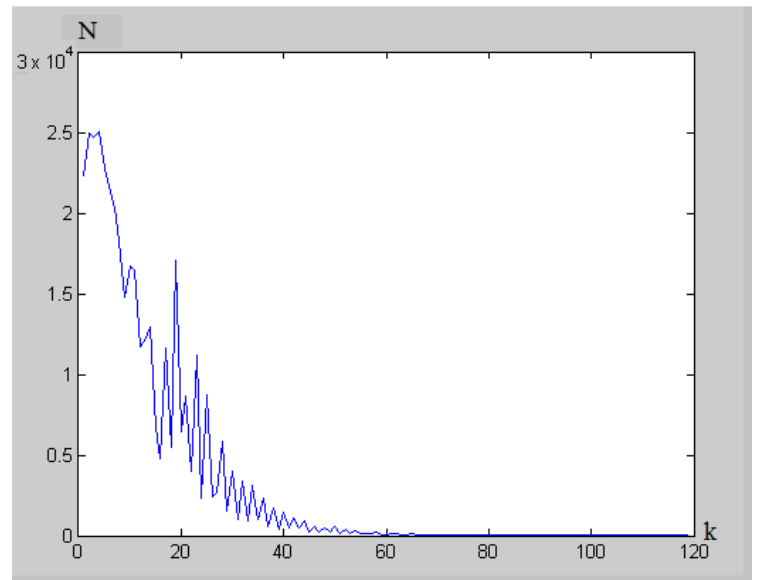

Fig. 5. Dependence of the objective function $N$ on the number of optimization step $k$ when finding the additional full compensation mode

As can be seen from the graph, the number of calls to the SPS-model has decreased by more than 2 times. Over 120 calls, a solution was reached in which the value of the objective function $N=0.212$. In fact, already over 60 calls, a small value of $N$ was reached and the interval for $k=0 \ldots 60$ is characterized by a continuous decrease in the objective function and the absence of horizontal sections in the plot, as observed in the previous case. The solution obtained under these conditions, however, is characterized by relatively large values of the optimization variables at the solution point, which correspond to the following values of the compensator capacitances:

$C_{a b}=3935.3 \mu \mathrm{F} ; C_{b c}=3555.5 \mu \mathrm{F} ; C_{c a}=3407.7 \mu \mathrm{F}$.

Figure 6 shows the temporal diagrams of currents in PTL with the specified parameters of the compensator. Here you can see that the currents are really balanced in amplitude and shifted by 120 electrical degrees relative to each other at a zero phase angle for phase A. Therefore, the power factors characterizing the operation of each source of electricity constitute the maximum unit value, which corresponds to the mode of full compensation of reactive power in the system.

The found second mode of full compensation of reactive power can be called additional, since it is characterized by extremely large values of the amplitudes of consumed currents. The amplitudes of the currents in PTL amount to $928.4 \mathrm{~A}$. This is more than two orders of magnitude greater than the amplitudes of $7.754 \mathrm{~A}$ for the first main mode.

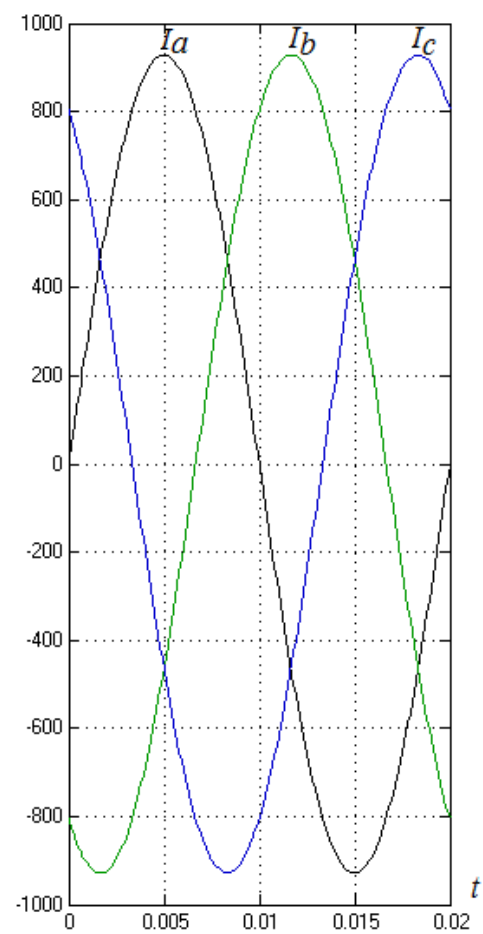

Fig. 6. Temporal diagrams of currents in PTL in the additional mode

The summarizing Table 1 presents a comparison of system and mode parameters characterizing both modes of full compensation of reactive power for the considered generalized three-phase system.

Table 1

Values of system and mode parameters in the main and additional modes

\begin{tabular}{|l|c|c|}
\hline \multicolumn{1}{|c|}{ Parameters } & $\begin{array}{c}\text { Main mode of } \\
\text { full reactive } \\
\text { power } \\
\text { compensation }\end{array}$ & $\begin{array}{c}\text { Additional mode } \\
\text { of full reactive } \\
\text { power } \\
\text { compensation }\end{array}$ \\
\hline $\begin{array}{l}\text { Capacitor capacitance } \\
C_{a b}(\mu \mathrm{F})\end{array}$ & 562.2 & 3935.3 \\
\hline $\begin{array}{l}\text { Capacitor capacitance } \\
C_{b c}(\mu \mathrm{F})\end{array}$ & 182.3 & 3555.5 \\
\hline $\begin{array}{l}\text { Capacitor capacitance } \\
C_{c a}(\mu \mathrm{F})\end{array}$ & 34.1 & 3407.7 \\
\hline $\begin{array}{l}\text { Current amplitude in PTL } \\
(\mathrm{A})\end{array}$ & 7.754 & 928.4 \\
\hline $\begin{array}{l}\text { Load voltage amplitude } \\
(\mathrm{V})\end{array}$ & 99.25 & 291.8 \\
\hline $\begin{array}{l}\text { Power supplied by each } \\
\text { source of electricity }(\mathrm{W})\end{array}$ & 387.7 & 46420 \\
\hline
\end{tabular}

Regarding the question of the adequacy of the results obtained, it can be noted that the existence of an additional mode of full compensation, as well as its stability, is fully proved by modeling on the SPS-model in the time domain, where the system, being dissipative [9], is described by differential equations in the space of state variables [10]. The question of the implementation of this mode for the considered option in practice will be complicated by the need to install very large capacitances of the compensator, to ensure the flow of large currents in the system, etc. However, with certain parameters of the 
system, the points characterizing both modes of full compensation may not be so separated by system and mode parameters. In such cases, the practical significance of the proposed approach will be that the implementation of both modes can be quite feasible in practice. Then the question of choosing the full compensation mode, which is characterized by more rational technical and economic indicators, will certainly arise.

\section{Conclusions.}

The studies performed suggest that the search optimization method using the SPS-model showed the possibility of the existence of two modes of full compensation of reactive power in a three-phase power supply system. In terms of optimization theory, this means that there is no global optimum in the solution of the full compensation problem, but there are two local optima. Physically, this is due to the ambiguity of the solution of the problem of synthesizing the parameters of the compensating device. Modeling in the state space confirms the stability of both modes, which are characterized by the maximum value of the power factor.

\section{REFERENCES}

1. Arrillaga J., Watson N.R., Chen S. Power system quality assessment. John Wiley, 2000. 300 p.

2. Acha E., Agelidis V.G., Anaya-Lara O., Miller T.J.E. Power Electronic Control in Electrical Systems. Newnes, 2002. 443 p. doi: 10.1016/B978-0-7506-5126-4.X5000-7.

3. Hofmann W., Schlabbach J., Just W. Reactive Power Compensation: A Practical Guide. John Wiley \& Sons, 2012. $274 \mathrm{p}$.

4. Azzam M., Mousa A.A. Using genetic algorithm and TOPSIS technique for multiobjective reactive power compensation. Electric Power Systems Research, 2010, vol.80, no.6, pp. 675-681. doi: 10.1016/j.epsr.2009.10.033.

5. Jeon S.-J., Willems J.L. Reactive power compensation in a multi-line system under sinusoidal unbalanced conditions. International Journal of Circuit Theory and Applications, 2011, vol.39, no.3, pp. 211-224. doi: 10.1002/cta.629.

6. Yagup V.G., Yagup E.V. Primenenie optimizatsionnykh metodov dlia resheniia zadach uluchsheniia pokazatelei elektricheskikh sistem [The use of optimization methods for solving problems of improving the performance of electrical systems]. Kharkiv, KNAME of A.N. Beketov Publ., 2017. 170 p. (Rus).

7. Chapra S.C., Canale R.P. Numerical methods for engineers. McGraw Hill, Higher Education, 2006. 926 p.

8. Nathews J.H., Fink K.D. Numerical methods. Prentice Hall, Upper Saddle River, 2001. 720 p.

9. Friedland B. Control system design: an introduction to state-space methods (Dover Books on Electrical Engineering). Dover Publications Inc. Mineols, New York, 2005. 620 p.

10. Chernykh I.V. Modelirovanie elektrotekhnicheskikh ustroistv v MATLAB, SimPowerSystems i Simulink [Modeling of electrical devices in MATLAB, SimPowerSystems and Simulink]. Moscow, Peter Publ., 2008. 288 p. (Rus).

Received 21.01.2019

V.G. Yagup ${ }^{1}$, Doctor of Technical Science, Professor,

E.V. Yagup ${ }^{1}$ Doctor of Technical Science, Associate

Professor,

${ }^{1}$ O.M. Beketov National University of Urban Economy in Kharkiv,

17, Marshal Bazhanov Str., Kharkiv, 61002, Ukraine, phone +380 577073114 ,

e-mail: kata3140@gmail.com

How to cite this article:

Yagup V.G., Yagup E.V. Research of the modes of full compensation of reactive power in a three-phase power supply system. Electrical engineering \& electromechanics, 2019, no.2, pp. 61-65. doi: 10.20998/2074-272X.2019.2.09. 